\title{
NOS CAMINHOS DE IANSÃ: CARTOGRAFANDO A SUBJETIVIDADE DE MULHERES EM SITUAÇÃO DE VIOLÊNCIA DE GÊNERO ${ }^{1}$
}

\author{
Silvia Regina Ramão \\ Stela Nazareth Meneghel \\ Carmen Oliveira \\ Universidade do Vale do Rio dos Sinos
}

\begin{abstract}
RESUMO: Este artigo tem como objetivo cartografar a subjetividade de mulheres em situação de violência de gênero perpetrada pelo companheiro. As ferramentas para esta cartografia consistiram em uma intervenção, por meio de oficinas, onde foi utilizada a narrativa de histórias. Dez mulheres em situação de violência de gênero, atendidas na organização não governamental de mulheres negras Maria Mulher/Porto Alegre, participaram das oficinas. Foram utilizados recursos artísticos, como a confecção e pintura de máscaras, técnicas corporais e dramatizações. Este artigo focaliza três encontros: o primeiro, onde as mulheres contaram suas histórias; o segundo, onde escutaram histórias de orixás femininos; e o terceiro onde foi oportunizado espaço para uma ritualização. Observou-se que essas mulheres estão submetidas a múltiplas violências que paralisam os movimentos do desejo fazendo com que permaneçam territorializadas nos papéis de mãe, esposa e cuidadora. Por outro lado, as oficinas possibilitaram a constituição de novos territórios e devires para além da violência. Palavras-chave: violência de gênero, empoderamento, subjetividade
\end{abstract}

\section{IN THE PATHS OF IANSÃ: MAPPING THE SUBJECTIVITY OF WOMEN WHO ARE VICTIMS OF GENDER VIOLENCE}

ABSTRACT: This article intends to map the subjectivity of women who are victims of gender violence perpetrated by their partners. The tools to compose this cartography consisted of a intervention, by means of a workshop where the narrative was used. The workshops were organized with the participation of ten women victims of gender violence, assisted by "Maria Mulher/Porto Alegre", which is a non-governmental organization for African Brazilian women. Artistic resources were also used, such as the manufacturing and painting of masks, physical expression exercises and dramatizations. This article focuses on three meetings of this workshop. The first one, where the women narrated their personal histories; the second one, where they were told the stories of female orixás [African-Brazilian deities]; and the third one, where space was given for the ritualization. It was observed that these women are submitted to multiple kinds of violence, which paralyzes their movements of desire, arresting and territorializing them in the roles of mother, wife and care-giver. On the other hand, the workshops made possible the constitution of new territories and possibilities of becoming beyond the violence.

Key-words: gender violence, empowerment, subjectivity

\section{INTRODUÇÃO}

Este artigo busca compreender as subjetividades de mulheres em situação de violência de gênero praticada pelo companheiro, cartografando os processos de produção do desejo a partir de uma intervenção grupal.

Os estudos sobre violência de gênero derivaram de pesquisas sobre a mulher e da contribuição do movimento feminista, que introduziu na discussão o conceito de patriarcado, contrapondo-se à abordagem funcionalista que, embora enxergasse as discriminações perpetradas contra as mulheres, situava seus papéis domésticos e públicos no mesmo nível, atribuindo-lhes igual potencial explicativo. Patriarcado foi definido como "um conjunto de relações sociais que tem uma base material e no qual há relações hierárquicas entre homens, e solidariedade entre eles, que os habilitam a controlar as mulheres. Patriarcado é, pois, o sistema masculino de opressão das mulheres" (Hartmann: 232 apud Saffioti, 1999).

No Brasil, por quatro séculos, foi predominantemente agenciado o sistema patriarcal, onde o homem detinha o poder sobre os bens, a família e a mulher. Às mulheres era reservado o mundo privado e aos homens o público. Tal segmentação estabelece estereótipos e gera diferentes formas de discriminação e desigualdade na sociedade (Fuks, 2002).

As feministas construíram a categoria gênero, 
Ramão, S.R.; Meneghel, S.N.; Oliveira, C. "Nos caminhos de lansã: cartografando a subjetividade de mulheres em situação de violência de gênero"

entendida como um conjunto de arranjos pelos quais a sociedade transforma a sexualidade biológica em produtos da atividade humana e no qual estas necessidades sexuais são satisfeitas. Gênero é um modo primordial de significar relações de poder. A partir desse conceito formulado por Rubin em 1975, a categoria gênero passou a ser amplamente utilizada nos estudos sobre mulheres, representando uma recusa ao essencialismo biológico e à imutabilidade implícita no velho aforisma: a anatomia é o destino (Saffioti, 1999). O conceito de gênero envolve quatro dimensões: o aspecto relacional; as representações sociais do que é ser homem e ser mulher, a dimensão normativa que estabelece interpretações dos significados dos símbolos e, em último lugar, a identidade subjetiva (Scott, 1990). A dimensão relacional do conceito de gênero auxiliou a descartar a noção de vitimização que impregnava os primeiros estudos sobre a violência contra a mulher.

Conceituamos violência como relação de força, conversão de uma diferença em uma relação hierárquica de desigualdade objetivando a exploração, a dominação, a opressão e a coisificação do ser humano (Chauí, 1985).

A violência contra a mulher, por sua vez, é qualquer ação ou conduta baseada no gênero, que cause morte, dano ou sofrimento físico, sexual ou psicológico, tanto no âmbito público como no privado (Claden, 2000). As violências baseadas em gênero são agudizadas pelas desigualdades sociais, ou seja, há uma sobreposição entre os sistemas de dominação/ exploração de classe, gênero e etnia (Brasil, 2003). As mulheres negras são as mais pobres e se encontram em piores condições de escolaridade, trabalho e moradia (OMS 2003). Os primeiros estudos sobre a violência contra a mulher postularam que a violência acontecia em todas as classes sociais, porém está se tornando um consenso a constatação de que "há um agravamento deste tipo de violência quando a mulher é negra, pelo racismo que gera outras violências adicionais" (Carneiro, 2003:11).

A evidência de que mulheres em situação de violência apresentam inúmeras repercussões em sua saúde física e emocional já foi constatada em inúmeros estudos (Heise, 1994), porém, os efeitos da violência na subjetividade das mulheres têm sido pouco pesquisados e compreendidos. Pensamos, ancoradas na esquizoanálise, que um dos determinantes da manutenção da violência baseada em gênero seja a estagnação dos processos de produção do desejo, impossibilitando a construção de novos modos de ser e existir no mundo. Desejo percebido como força produtiva e criativa, de caráter revolucionário, imanente a outras forças animadoras da sociedade e da história (Baremblitt, 2002).
Para compreender os processos de produção do desejo, faz-se necessário explicitar alguns conceitos ferramentas, como o de subjetividade. A subjetividade é essencialmente produção social, conforme Guattari (1992), que a define enquanto composição de fluxos de afeto, intensidades pré-verbais da ordem do invisível, evocados por instâncias inter-humanas manifestas pela linguagem e instâncias identificatórias relativas a interações institucionais, sociais e culturais e, ainda, dispositivos como a música e as artes. Os fluxos de afetos mobilizados provocam a ativação do desejo e buscam tomar forma e sentido constituindo novos territórios existenciais. Territórios existenciais são as diferentes maneiras do sujeito perceber-se no mundo.

Neste sentido, a subjetividade é rizoma, que Deleuze e Guattari (1995) definiram como um tecido de multiplicidades e de intensidades (que dizem respeito ao território constituído) do qual emergem linhas de segmentaridade e linhas de fuga (desterritorializantes), em função das quais o rizoma muda de natureza e cria novos caminhos, que podem oferecer resistência à homogeneização serializante do capitalismo.

Guattari e Rolnik (1996) fazem referência a dois planos diferentes que compõem a subjetividade. Um plano da ordem invisível, também denominado plano molecular e outro da ordem do visível ou plano molar. No plano invisível, não existe ordem, estrutura, identidade, modelo, tampouco gênero, mas sim fluxos que, segundo os movimentos do desejo, buscam constituir máscaras, engendrando sempre diferentes formas. O plano visível é da ordem da forma, da consciência, das representações e do imaginário. Neste plano há fronteiras definidas, como no espaço da história e sua reificação.

Segundo Rolnik (1989), a produção do desejo acontece através de três movimentos, articulados entre o plano visível e o plano invisível. O primeiro movimento corresponde à linha dos afetos, da ordem do invisível e produz desassossego; o segundo movimento constitui a linha de simulação, de ensaio de uma nova forma, de um novo território. Neste momento o desejo vai sendo acionado dando passagem para uma nova forma, ainda no plano dos afetos, mas já ganhando uma máscara no plano visível. No terceiro movimento, no plano molar, uma nova ordem e novos territórios se constituem.

O desejo é potência, produção e criação. Os movimentos do desejo são engendrados a partir do encontro com o outro e podem provocar singularização, que acontece quando o sujeito estabelece uma relação de expressão e criação e se reapropria dos componentes da subjetividade. Em síntese, a subjetividade é plural, polifônica, é produção 
de novos sentidos, mobilizados por agenciamentos coletivos de enunciação. Os agenciamentos coletivos de enunciação são processos produtores de subjetividade que implicam máquinas de expressão de natureza extrapessoal (sistemas maquínicos, econômicos, sociais, ecológicos) e de natureza infrahumana, infrapsíquica e infrapessoal (sistemas de sensibilidade, de afeto, de desejo) (Guattari, 1992; Guattari e Rolnik, 1996).

A ordem do visível engendra, por vezes, uma homogeneização, que produz um certo tipo de subjetividade, a qual diz respeito a um mercado de valores onde a pessoa tem um preço, é força de trabalho e de consumo. Esta homogeneização produz o achatamento do desejo e da subjetividade, que se efetua segundo mecanismos de segregação, infantilização e culpabilização (Guattari e Rolnik, 1996).

No presente estudo, trabalhamos, por um lado, com o plano molar buscando entender as representações que compõem o imaginário da mulher em situação de violência; e, por outro, o molecular, procuramos compreender as intensidades mobilizadas nas mulheres em situação de violência. Queríamos saber se a intervenção que inventamos constituiu um agenciamento de enunciação instigador da construção de novos devires, para além da violência.

\section{TRAJETÓRIA METODOLÓGICA}

Esta pesquisa é parte do projeto denominado Histórias de resistência de mulheres (Meneghel, Farina e cols, 2003), ligado ao PPG de Ciências da Saúde, aprovada pelo Comitê de Ética da Universidade do Vale do Rio dos Sinos (CEP/UNISINOS). Trata-se de uma intervenção de cunho qualitativo, onde se buscaram elementos para cartografar a subjetividade de mulheres em situação de violência de gênero. Buscamos inspiração no método cartográfico em vários momentos do trajeto metodológico: na escuta às mulheres, na postura participante da equipe de pesquisa, na construção da intervenção pautada nos elementos da religião africana, na valorização de todos os elementos que emergiram a partir da intervenção, na construção simultânea da ferramenta e do mapa. Fonseca e Kirst (2003:12) ressaltam que, na cartografia, "os procedimentos metodológicos sustentam-se no paradigma ético-estético onde não se dissocia sujeito-objeto, e o conhecimento também é auto-conhecimento, onde pesquisador e objeto são entes que formam uma unidade a partir de desejo $e$ implicação".

A cartografia não determina uma metodologia, mas "propõe uma discussão metodológica que se utiliza na medida que ocorrem encontros entre sujeito e objeto em uma perspectiva de acolher a vida em seus momentos de expansão" (Kirst e Giacomel, 2003:91).

A Organização de Mulheres Negras Maria Mulher, local onde se realizou esta pesquisa, é uma entidade que atua na vila Cruzeiro do Sul, em Porto Alegre, uma região caracterizada como área de exclusão social, com 64952 habitantes, a maioria afrodescendentes (Fesc, 1999). O objetivo da organização é o de lutar pelos direitos das mulheres e pela melhoria das condições de vida dos afrodescendentes. Uma das pesquisadoras é uma mulher negra, militante do movimento de mulheres negras, envolvida no debate sobre a questão racial, além de ter construído uma trajetória no trabalho social, comunitário e voluntário.

As participantes da pesquisa foram dez mulheres em situação de violência de gênero e moradoras de uma região considerada área de exclusão social, caracterizada como: $97 \%$ das pessoas vivendo sem saneamento, $18 \%$ não alfabetizados, precária inserção profissional (desemprego, subemprego ou emprego precário), 47\% vivendo abaixo da linha de pobreza e presença 70\% de mulheres chefes-de-família (FESC, 1999). Cinco mulheres eram de etnia negra e três destas mulheres soropositivas. A maioria delas iniciou a vida sexual na adolescência e enfrenta dificuldades na relação com o parceiro.

A pesquisa foi construída nos moldes de uma intervenção grupal, baseada na técnica de oficinas, entendidas como dispositivos de trabalho coletivo, determinantes e determinados pelas práticas históricosociais, utilizados para agenciar mudanças na vida das participantes, propondo reinventar o cotidiano (Rauter, 2000). As oficinas constituíram espaços de conexão entre a produção do desejo, a ritualização, a expressão verbal e artística, percebendo o desejo como produtor do real e de novos devires sem violência.

Este artigo focaliza três encontros desta oficina: o primeiro, onde as mulheres contaram suas histórias e produziram máscaras; o segundo, onde escutaram histórias de orixás femininos; e o terceiro, onde ocorreu a ritualização destas histórias. Usamos elementos da cartografia como recurso exploratório e de interpretação dos achados e das vivências que aconteceram nas oficinas. Todas as produções que emergiram no espaço das oficinas - a arte, as máscaras, as narrativas, a linguagem corporal, as ritualizações, a participação e mesmo o abandono (duas mulheres desistiram de participar) - serviram como fontes para compreensão do processo da pesquisa.

\section{CARTOGRAFANDO VIOLÊNCIAS...}

As oficinas iniciaram com o relato das histórias de vida das participantes, histórias que foram contadas e recontadas muitas vezes durante o trajeto. O 
Ramão, S.R.; Meneghel, S.N.; Oliveira, C. "Nos caminhos de lansã: cartografando a subjetividade de mulheres em situação de violência de gênero"

enfrentamento à violência parece iniciar, como em outros grupos, com a constatação da presença da violência na própria vida. Relembrar as dores é difícil e faz chorar. Encolhidas e cabisbaixas, as mulheres começaram a contar suas histórias. Dinâmicas de apresentação e relaxamento trataram de flexibilizar um corpo que se enunciava duro. Um corpo doído, cansado, ombros caídos, onde as marcas da violência apareciam. Nesse corpo endurecido, delineavam-se linhas de territorialização capazes de submeter, silenciar, calar, reproduzir estereótipos, fazendo com que as mulheres produzam uma identidade serializada, homogênea.

Nas histórias de vida apareceu a situação de privação e as diferentes violências entranhadas na vida destas mulheres e banalizadas no cotidiano. Em algumas falas, a entonação era mecânica, como se tratassem de outra pessoa. Porém, mesmo com omissões e segredos que permaneceram velados, todas as mulheres revelaram alguma face das violências que estavam vivendo - a estrutural, a interpessoal, a da doença. Observou-se que ao narrar as suas vidas, as mulheres omitiram-se como personagens de suas histórias. Os papéis principais pertencem aos maridos e aos filhos. Elas se vêem como coadjuvantes. As dores e as angústias são secundarizadas pelas dores e angústias dos outros. Ao serem perguntadas sobre elas, respondem com a voz do outro, territorializadas naquilo que a sociedade designou pertinente ao 'feminino' e ensinadas a nutrir, a alimentar, a cuidar, em suma, a não ter voz. Nesse contexto social, práticas de socialização aliadas à produção capitalística do desejo agenciam nas mulheres o devir da maternidade, do cuidado e da submissão. Elas atuam de acordo com as referências do feminino na sociedade e na família engendradas pelo patriarcado e assimiladas sem questionamento. Guattari e Rolnik (1996:23) referem que, no capitalismo, o capital se ocupa da sujeição econômica e a cultura, da sujeição subjetiva. "No fundo", dizem os autores, "só há uma cultura: a capitalística, etnocêntrica e intelectocêntrica, pois separa os universos semióticos das produções subjetivas. Por outro lado, há muitas maneiras de a cultura ser etnocêntrica, não apenas na relação racista, masculina, branca e adulta".

As mulheres se disseram impotentes frente às violências: "a situação só se resolve quando o homem é preso ou morre". Apenas uma delas apontou como perspectiva para romper com a violência, a denúncia aos órgãos policiais. Segundo uma das coordenadoras de Maria Mulher, "o encaminhamento ao órgão policial é contraproducente, podendo inclusive induzir a uma carga maior de violência por parte do companheiro, na medida em que a ação policial é morosa ou omissa. A polícia, ao receber uma denúncia de violência doméstica, atua de modo diferente, de acordo com a etnia de quem efetua a queixa: se é uma mulher negra, eles intimidam e batem no marido agressor, se é uma mulher branca, não fazem nada. Estes fatos contribuem para a baixa confiabilidade da instituição policial." Carneiro (2003) e Porto (2004) referem que as mulheres negras têm maior dificuldade de realizar queixa policial, por saberem a forma repressiva como a polícia trata os negros.

Além das dificuldades econômicas, outras situações fazem com que essas mulheres sintam-se deprimidas, cansadas, ansiosas e doentes, podendo-se arrolar o desemprego, a baixa qualificação profissional, a violência do tráfico de drogas, as altas taxas de mortalidade masculina por homicídios, especialmente de jovens, os elevados índices de doenças relacionadas com a pobreza, a feminização da AIDS, as relações conjugais instáveis, a sobrecarga com o cuidado das famílias, sobrepondo-se aos desrespeitos que lhes são infligidos no cotidiano por serem mulheres, pobres e negras.

Alia-se a este quadro, a violência simbólica das instituições que as rechaçam, estigmatizam, rotulam, culpabilizam, reforçando a situação de menoridade das mulheres. A violência simbólica, segundo Bourdieu (2002:50), é "a forma de poder que se exerce sobre os corpos, diretamente, e como que por magia, sem qualquer coação física; mas esta magia só atua com o apoio de predisposições colocadas como molas propulsoras, nas zonas mais profundas dos corpos". A dominação simbólica - quer seja de etnia, gênero, cultura, língua, ou outra, se exerce além das decisões da consciência e da vontade e pressupõe uma aceitação tácita por parte dos dominados, trata-se de lei social convertida em lei incorporada. Embora o reconhecimento da dominação implique sempre em um ato de conhecimento, a tomada de consciência, por si só, não significa a liberação dos oprimidos, "já que a inscrição das estruturas sociais no corpo resulta em opacidade e inércia" (Bourdieu, 2002:53). A violência simbólica está presente no dia-a-dia destas mulheres e na relação das mesmas com os serviços de saúde, muitas vezes de hostilidade declarada. Esta violência foi constatada por meio dos entraves no acesso destas mulheres aos serviços de saúde, muitas vezes só obtido após interferência direta da ONG. Não ser reconhecida como pessoa de direito caracteriza a realidade destas mulheres, intensifica a situação de vulnerabilidade e compõe o mecanismo que Guattari e Rolnik (1996) chamam de segregação e infantilização, em que se produz, respectivamente, o isolamento social da pessoa e a incapacidade para falar em voz própria.

O sentimento de impotência frente à vida, a incapacidade para mudar o destino, a queixa e a 
expectativa colocada no assistencialismo como forma de resolução dos problemas são decorrência dos processos de subjetivação que paralisam, homogeneízam, congelam os processos de produção do desejo. No grupo de mulheres participantes da oficina percebemos agenciamentos recorrentes que ativam as marcas de submissão, de dependência, de dor e de angústia. A magia que o poder simbólico desencadeia, diz Bourdieu (2002:51) "assume muitas vezes a forma de emoções corporais - vergonha, humilhação, timidez, ansiedade, culpa - denunciando a cumplicidade subterrânea de um corpo que se subtrai às diretivas da consciência e da vontade". Desta forma, há uma perda de potência (Naffah Neto,1994), no sentido de que o psiquismo é privado do seu poder de criação, o qual "é sempre dissidente, transindividual, transcultural" (Guattari e Rolnik, 1996:36). A interceptação do desejo (Oliveira, 1994) é um dos mais eficazes mecanismos de controle em nossa sociedade, sendo que a violência catalisa fluxos de obediência e de passividade em que os sujeitos são programados para agenciar o tu deves. Nessas circunstâncias, podese falar de uma subjetividade territorializada pelos agenciamentos do feminino impostos pela cultura patriarcal. O devir agenciado é o da suportação, em que se carrega o que há de mais pesado (Nietzsche, 1986:43)

AMINA E IANSÃ - PARALELOS E LINHAS DE FUGA... Como agenciar o desejo e mudar essa cartografia? Como ativar as possíveis linhas de fuga? Propusemos como dispositivos para alavancar mudanças, a confecção de máscaras e as narrativas de histórias. A proposta para moldar as faces com gaze gessada causou espanto, amenizado com os primeiros resultados: máscaras com grandes olhos assustados e lágrimas. O grupo de pesquisa foi cuidadoso dividindo-se nas tarefas de fazer as máscaras e na escuta. A vergonha inicial dissipou-se, transformando-se em um sentimento de comoção partilhado pela equipe e usuárias. O clima era de acolhimento e troca. A plasticidade deste processo relembra os três movimentos do desejo: afetação pelo outro/mobilização de afetos, simulação e constituição de novos territórios. A criação das máscaras constituiu o segundo movimento do desejo, onde após experimentar diferentes personas e simular possibilidades, por meio da máscara, se divisou um novo território, abandonando a persona-vítima.

Contar histórias foi outro dispositivo para provocar diferenças capazes de disparar o desejo. Contamos histórias das orixás a partir da concepção Iorubá (Leal, 1988, Parrinder, 1986) e a de Amina, uma mulher nigeriana, condenada a ser apedrejada por adultério, mas absolvida após uma grande mobilização mundial. O que nos guiou neste percurso foi a intenção de agenciar outras formas de subjetividade, a partir da cultura afro-brasileira, que oferece outras possibilidades de viver e explorar o ser mulher. As histórias de orixás se desenvolveram em três momentos: no primeiro deles foram contadas as histórias; no segundo, foram observadas imagens das deusas; e no terceiro, organizou-se a ritualização.

As mulheres começaram a esboçar um discurso que rompia com o enunciado dos primeiros encontros calcado na queixa e na vitimização. Elas expressaram a necessidade de cuidado, descartando o assistencialismo e a menoridade: "a gente que é mãe cuida bem dos outros, mas não cuida da gente, tem angústia, depressão, medo, e precisa de cuidado e apoio". Aconteceram outros movimentos como o de constatar a violência em que vivem, mesmo em um país, como o Brasil, onde a lei não condena as mulheres à morte: "Agora aqui não tem lei, mas quantas vezes os maridos se acham no direito de matar as mulheres, mesmo depois de separados. Então quer dizer que é horrivel quando é lei, quando não é obrigado não é feio, não é monstruoso."

As histórias das deusas constituíram um dispositivo que possibilitou o aflorar de modos de expressão dissidentes, em relação aos modos de expressão dominantes. A vivência que a oficina oportunizou, tanto dos aspectos vulneráveis das orixás, quanto dos aspectos de poder, abriu perspectivas de singularizações. Quando procuramos entender as semelhanças com as orixás elas disseram: "que a gente vive, ama, que a gente é ciumenta, que a gente tem filho, né?" "Que a gente tem algum poder." "Então é tudo bem parecido, nós, com elas."

Encarnar o papel de uma deusa, vestindo-se ritualmente como ela - uma prerrogativa das mulheres negras curadoras no espaço do candomblé - pareceunos a ativação de uma linha de força, capaz de desterritorializar subjetividades homogêneas, ativando outros devires. As mulheres se adornaram com os tecidos e adereços da orixá escolhida. Compuseram rebuscados turbantes, como que saídos de ilustrações étnicas. Reviveram histórias de outras mulheres - avós, mães, tias, vizinhas, delas mesmas - em territórios de religião: candomblé e batuque. Contrapuseram às histórias que contamos, as narrativas delas, podendo dizer "não é bem assim", "eu sei". Bonitas e alegres, os corpos mais flexíveis, despidas as máscaras de dor e autocompaixão, elas discutiram coletivamente outras saídas, outras negociações, outras lutas. Em cada encontro a equipe saía comovida, impactada com as violências e emocionada com as possibilidades existenciais totalmente inusitadas que começaram a se delinear. Da necessidade de corresponder à demanda assistencialista inicial das mulheres, a 
Ramão, S.R.; Meneghel, S.N.; Oliveira, C. "Nos caminhos de lansã: cartografando a subjetividade de mulheres em situação de violência de gênero"

intervenção passou a encontrar outros sentidos, uma vez que permitiu dar língua a afetos antes imobilizados; enfim, dar passagem para o desejo, para a possibilidade de ver a vida além da dor, como enunciou uma delas: "Ah, eu sofro, eu tenho os meus problemas mas eu sou feliz, eu tenho meus filhos, minha família, bem ou mal uma casa".

O ritual possibilita vivenciar por meio do símbolo, situações de estagnação produzidas pelos sistemas sociais de dominação/exploração. São acontecimentos especiais da sociedade que podem servir como território, cenário e ação para resolver impasses, na medida que permitem a realização de uma performance em que os participantes experimentam intensamente esta situação (Peirano, 2003). De forma semelhante, o jogo possibilita, através do aspecto teatral que se aprenda o caráter artificial criacionista da produção de subjetividade (...) permite que se produza um clima de autenticidade existencial acrescido de uma liberdade de jogo e simulacro (Guattari, 1992: 18). O ritual possibilita a transformação da violência em produtos simbólicos (Mafessoli, 1993; Meneghel, Barbiani e cols, 2003). Vestindo-nos ritualmente como Iansã, de alguma forma, nos apoderamos dos poderes da deusa. Segundo Guattari e Rolnik (1996: 72):

(...) a subjetividade dos negros que reinventam um sistema religioso como o candomblé, significa uma referência mítica (...) esta prática tem um caráter criativo de invenção de uma espécie de religião num contexto, ao fim e ao cabo, muito modernista. Aliás, isso parece ser uma característica da situação do continente latino-americano de modo geral. Ele não foi completamente devastado pelas semióticas capitalísticas e dispõe de reservas extraordinárias de meios de expressão não logocêntriocos, podendo se articular em formas de criação totalmente originais.

A ritualização das orixás deu vazão à potencialização do desejo que engendra novos processos de singularização e favorece a processualidade da vida (Nietzsche apud Naffah Neto, 1994).

Em síntese, para que as mudanças aconteçam, não basta que seja ativado apenas o plano molar - o plano das representações sociais -, mas é imprescindível que aconteça o processo de singularização, que corresponde ao plano molecular. As revoluções moleculares podem engendrar uma transformação radical na sociedade, uma vez que atingem o sistema em uma de suas bases, ou seja, na produção de subjetividade, que irá permitir às mulheres tomar posse de seus corpos, de suas vidas, de seus desejos e lutar pelos direitos que têm e precisam ver efetivamente exercidos na sociedade.

Assim divisamos o movimento que denominamos devir-Iansã.

\section{SOMOS TODAS IANSÃS}

Junto às brincadeiras, às lágrimas, às histórias - das mulheres, de Amina, das orixás, vimos se potencializar algumas linhas de fuga agenciando o devir Iansã. Escolhemos Iansã porque foi a orixá com a qual todas nos identificamos. Iansã é a orixá guerreira e segundo as mulheres, "as filhas de Iansã não fogem da briga". São sedutoras, bonitas, charmosas, mães protetoras e mulheres apaixonadas. Iansã é a encarnação do desejo de potência em sua plenitude, cujas manifestações se expressam em depoimentos do tipo: "somos todas mulheres, vivemos, amamos, choramos, temos filhos e cuidamos deles, somos fortes".

Assim como o sistema social agencia o devir mãe/vítima, as histórias das orixás agenciaram devires subversivos que engendram novas formas de ser, agir, desejar, criar. O devir Iansã delineou-se quando as mulheres constataram indignadas que a violência de gênero não deve ser tolerada, mesmo quando legitimada pelo Estado e pelas leis. Foi a partir destas reflexões que elas abandonaram as queixas e passaram a discutir possibilidades no cuidado com os filhos, aconselhando-se quanto ao manejo em relação ao absenteísmo escolar, ao envolvimento destes jovens com drogas e furtos e, pela primeira vez, mostraram firmeza para estabelecer limites.

Ao contar as histórias, passaram de ouvintes a contadoras, pois interrompiam nossas falas com seus relatos. Uma das mulheres disse que estudara o tema algum tempo e nos deu um depoimento mostrando o quanto conhecia e vivia a religiosidade africana. Essa mulher manteve-se freqüentando a instituição, trouxe o marido para atendimento, o que fez repensar as propostas de atenção da ONG, e declarou terem cessado os episódios de violência física perpetrados pelo companheiro. Todas as mulheres do grupo ficaram mobilizadas pelas histórias das orixás, inclusive as pesquisadoras e as que pertenciam a outras religiões.

O último encontro foi uma celebração, no qual fizemos a devolução de alguns aspectos das oficinas, mostrando a elas a pré-edição das fitas de vídeo. As oficinas estimularam a reativação dos laços sociais, recuperados por várias das participantes que passaram a se encontrar fora do espaço da instituição, constituindo novas redes de amizade, escuta e apoio. A maioria delas se inseriu em alguma atividade da ONG, nas oficinas ou nos cursos. Iniciaram a traçar 
planos de vida, incluindo o aspecto profissional. Duas delas não retornaram.

As mulheres que estavam sendo agredidas superaram o problema da violência física. Constatamos no momento da redação deste trabalho que a violência psicológica se mantinha na vida de algumas das participantes ainda ligadas à ONG, assim como a violência das instituições que atendem a essa população.

\section{OS IBEGIS E O DEVIR CRIANÇA}

Os Ibegis são representados na mitologia africana por dois gêmeos que simbolizam o aspecto criança presente no interior de cada ser humano. Trazem consigo as idéias de inocência, de ingenuidade e de pureza infantis. Os Ibegis acenam com a possibilidade sempre presente do ser humano de reparar as feridas, de romper com a situação de vitimização e de refazer sua vida. Os Ibegis foram personificados nos aspectos lúdicos das oficinas, nas diferentes manifestações artísticas criadas em grupo e na presença dos filhos das mulheres, especialmente o menino deficiente auditivo que filmou a celebração final, rompendo com suas limitações físicas.

Nietzsche, em Zaratustra, relata as metamorfoses a que o espírito humano necessita vivenciar, onde a terceira metamorfose representa o devir criança: a inocência é a criança, o esquecimento, um novo começo, um novo jogo, uma roda que gira por si mesma, um movimento inicial, um sagrado dizer sim. Sim meus irmãos, para o jogo da criação é preciso dizer um sagrado sim (1986:45).

Assim como as máscaras permitiram ensaio e alternância das personas de vítima, de mãe, de guerreira, também nos permitiram um agenciamento do devir-criança. Brincando, fizemos o jogo de montar e desmontar personagens e repertórios. Talvez, por isso, em algumas tradições das religiões africanas os orixás são representados em diferentes idades, velho/ a, adulto/a, criança. Na cosmovisão africana a processualidade da vida é o mais importante, viver é o fazer das pessoas, guiar é o fazer dos orixás. Contudo, as possibilidades de viver e experimentar nos são roubados pelo capitalismo, ao controlar o tempo e a vida, e os agenciamento de como se deve viver, amar, sentir, impedindo a exploração, a criatividade e o lúdico.

O jogo permite exercitar esta capacidade esquecida: criar dispositivos que agenciem o devircriança, enfim, a capacidade de montar e desmontar os sonhos, rir e começar de novo (Oliveira, 1994).

\section{CONSIDERAÇÕES FINAIS}

As diferentes violências (físicas, emocionais simbólicas; de classe e de raça) a que estão sujeitas as mulheres, acentuam a situação de opressão e vulnerabilidade, em especial, a das mulheres negras.

Nas oficinas, pudemos constatar o deslocamento do 'eu devo' para o 'eu quero' em uma intervenção que não privilegiou a constatação da violência física baseada em gênero, mas acenou com a possibilidade de vivenciar situações e expressá-las por meio da narrativa, da arte e do ritual.

Abrir espaço para a dimensão subjetiva constitui um enfoque fundamental na construção de novas formas de atenção a mulheres em situação de violência baseada em gênero, oportunizando espaços de escuta e a experimentação de outros fazeres.

Na construção de estratégias de intervenção, é importante o uso de elementos do domínio popular conhecidos da população, destacando-se o papel das narrativas das orixás como dispositivo de produção de outras subjetividades. No trajeto da cartografia, percebemos a violência como uma forma radical de impedir a criação de novos devires. As oficinas de histórias de orixás mostraram-se capazes de instaurar processos singulares de subjetivação, agenciando linhas de fuga atravessando e constituindo novos territórios e lançando mão de recursos que mobilizaram estratégias de resistência para além do ressentimento e deixaram emergir a potência, por meio da arte, da dramatização e do ritual, sem esquecer o acolhimento, a escuta, o vínculo e os elementos do domínio da cultura popular.

O uso da cartografia em uma pesquisa inserida no campo da saúde coletiva representa um elo de aproximação e de fecundação interdisciplinar entre os campos do conhecimento da psicologia e saúde coletiva, ou seja, esta pesquisa também representa a tentativa de produzir conhecimento no encontro entre duas disciplinas: a saúde coletiva e a psicologia social.

NOTA

${ }^{1}$ Artigo desenvolvido a partir da dissertação de mestrado de Silvia Regina Ramão.

\section{REFERÊNCIAS}

Baremblitt, Gregório. (2002). Compêndio de Análise Institucional e outras correntes - teoria e prática. $5^{\text {a }}$. ed. Belo Horizonte: Instituto Félix Guattari.

Bourdieu, Pierre. (2002). A Dominação Masculina. $2^{\mathrm{a}}$. ed. Rio de Janeiro: Bertrand do Brasil.

Brasil. Secretaria Especial de políticas para as mulheres. (2003). Programa de prevenção, assistência e combate a violência contra a mulher - Plano Nacional: diálogos sobre a violência doméstica e de gênero: construindo políticas para as mulheres. Brasília: Secretaria Especial de Políticas para as Mulheres. 
Ramão, S.R.; Meneghel, S.N.; Oliveira, C. "Nos caminhos de lansãa: cartografando a subjetividade de mulheres em situação de violência de gênero"

Carneiro, Sueli. (2003). Mulheres negras, violência e pobreza, In: Secretaria Especial de políticas para as mulheres. Programa de prevenção, assistência e combate a violência contra a mulher - Plano Nacional: diálogos sobre a violência doméstica e de gênero: construindo políticas para as mulheres. Brasília:Secretaria,: 11-17.

Chauí, Marilena. Participando do debate sobre mulher e violência. Perspectivas antropológicas da mulher. Rio de Janeiro: Zahar, (4):23-62.

Comitê Latino-Americano e do Caribe para a defesa dos direitos da mulher. (2000). Questão de Vida balanço regional e desafios sobre os direitos das mulheres a uma vida livre de violência. Lima: CLADEN.

Deleuze, Giles \& Guattari, Félix. (1995). Mil platôs. vol. 1. Rio de Janeiro: Ed. 34.

Fundação de Educação Social e Comunitária. (1999). Conheça um pouco mais sobre a região 10 - Cruzeiro. Porto Alegre: Prefeitura Municipal.

Fonseca, Tânia Mara \& Kirst, Patrícia Gomes. (2003). Cartografias e devires: a construção do presente. Porto Alegre: Editora da UFRGS.

Fuks, Lúcia Barbero. (2002). Diferentes momentos da evolução feminina, In: Alonso, Sílvia L.; Gurfinkel, Aline C. ; Breyton, Daniele M.(orgs.). Figuras Clínicas do Feminino no mal-estar contemporâneo, São Paulo: Escuta: 105-114.

Guattari, Félix. (1992). Caosmose - Um novo Paradigma Estético. Rio de Janeiro: Ed.34.

Guattari, Félix \& Rolnik, Suely. (1996). Micropolítica: Cartografias do desejo. Petrópolis: Vozes: RJ. 4ª ed.

Heise, Lori. (1994). Violência e Gênero: uma epidemia global. Cadernos de Saúde Pública, (supl.1):13546.

Kirst, Patrícia Gomes; Giacomel, Angélica Elisa e cols. Conhecimento e cartografia: tempestade de possíveis. In: Fonseca, Tânia Mara \& Kirst, Patrícia Gomes. Cartografias e devires: a construção do presente. Porto Alegre: Editora da UFRGS,2003: 91-102.

Leal, Eneida. (1988). Os Orixás no Brasil. Brasil: Spala Editora.

Mafessoli, Michel. (1993). Ritual y la vida cotidiana como fundamentos de las historias de vida. In: Marinas
José Miguel \& Santamarína, Cristina. (org.) La historia oral: métodos y experiencias. Madrid: Mistral: 109117.

Meneghel, Stela N \& Farina, Olga. (2003). Histórias de resistência de mulheres. Pesquisa em desenvolvimento na UNISINOS. São Leopoldo:UNISINOS.

Meneghel, Stela N; Barbiani, Rosângela e cols. (2003). Impacto de grupos de mulheres em vulnerabilidade de gênero. Cadernos de Saúde Pública, 19(4),:955-964.

Naffah Neto, Alfredo. (1994). Psicoterapia em busca de Dionísio: Nietzche visita Freud. São Paulo: EDUC/ Escuta.

Nietzsche, Friedrich W. (1986). Assim falou Zaratustra: Um livro para todos e para ninguém. Rio de Janeiro: Civilização Brasileira, $4^{\mathrm{a}}$ ed.

Oliveira, Carmem S. Brasil: (1994). Anão ou herói? Barbarói.Santa Cruz do Sul, vol.1,:63-73.

OMS. (2003). Informe Mundial sobre la violencia y la salud. Krug E (editor) OMS: Washington.

Parrinder, Geoffey. (1986). África. Lisboa: Verbo.

Peirano, Mariza. (2003). Rituais- ontem e hoje. Rio de Janeiro: Zahar.

Porto, Janice Regina Rangel. (2004). Violência contra a mulher: expectativas de um acolhimento humanizado. Dissertação de Mestrado Universidade Federal do Rio Grande do Sul. PP Graduação em Enfermagem.

Rauter, Cristina. (2003). Oficinas para quê? In: Amarante, Paulo (org.) Ensaios - Subjetividade, saúde mental, sociedade. Rio de Janeiro: FIOCRUZ.:267-278.

Rolnik, Suely. (1989). Cartografia Sentimental: Transformações contemporâneas do desejo. São Paulo: Estação Liberdade.

Safiotti, Heilieth. (1999). Gênero e Patriarcado. São Paulo: PUC-SP. Texto não publicado.

Scott, Joan. (1990). Gênero: uma categoria útil nas análises. História, Educação e Realidade. Porto Alegre, $16(2),: 5-22$. 
Silvia Regina Ramão.

Psicóloga, Mestranda em Saúde Coletiva.

Endereço para correspondência PPG em Ciências da Saúde/Universidade do Vale do Rio dos Sinos. Av. Unisinos, 950 Bairro Cristo Rei - CEP 93022-000 -

São Leopoldo - Rs - Brasil O e-mail da autora é: silviaramao@ig.com.br

Stela Nazareth Meneghel. Professora orientadora e pesquisadora do PPG Ciências da Saúde/UNISINOS O e-mail da autora é: meneghel@bios.unisinos.br

Carmen Oliveira. Professora co-orientadora e pesquisadora do $P P G$ Ciências da Saúde/UNISINOS

\section{Silvia Regina Ramão}

Stela Nazareth

Carmen Oliveira

No caminho de Iansã: cartografando a subjetividade de mulheres em situação de violência de gênero

Recebido: 18/08/2004

$1^{\text {a }}$ revisão: 17/12/2004

Aceite final: 28/06/2005 